\title{
Wogonoside induces apoptosis in Bel-7402, a hepatocellular carcinoma cell line, by regulating $\mathrm{Bax} / \mathrm{Bcl}-2$
}

\author{
YUSHENG LI $^{1 *}$, MIN TU $^{2 *}$, CHAO CHENG $^{1}$, JIAN TIAN $^{1}$, FANGJIE ZHANG $^{1}$, ZHENHAN DENG $^{1}$, \\ XUAN'AN LI ${ }^{1}$, ZHONGKUI LI ${ }^{3}$, YANPING LIU ${ }^{3}$ and GUANGHUA LEI ${ }^{1}$ \\ ${ }^{1}$ Department of Orthopaedics, Xiangya Hospital, Central South University, Changsha, Hunan 410008; \\ ${ }^{2}$ Department of Orthopaedics, Second People's Hospital of Jingmen, Jingmen, Hubei 448000; \\ ${ }^{3}$ Department of Cell Biology, School of Life Sciences, Central South University, Changsha, Hunan 410008, P.R. China
}

Received July 18, 2014; Accepted April 15, 2015

DOI: $10.3892 / \mathrm{ol} .2015 .3408$

\begin{abstract}
The anticancer effect of Scutellaria baicalensis extract has recently become a topic of interest. In this study, the anticancer effects and underlying mechanisms of wogonoside, the main constituent of Scutellaria baicalensis, were investigated in a human hepatocellular carcinoma (HCC) cell line in vitro. The effects of wogonoside on the proliferation, cell cycle progression and apoptosis of hepatocellular carcinoma cells were examined. Western blotting was employed to analyze the proteins associated with the biological effects of wogonoside. Wogonoside exerted anti-proliferation properties in vitro. HCC cell growth was attenuated by wogonoside $(8 \mu \mathrm{M})$ treatment. Cell cycle progression analysis and DNA ladder assay revealed that apoptosis was enhanced in wogonoside-treated cells and that cell cycle arrest occurred in the G2/M phase. It was also demonstrated that increased apoptosis was accompanied by increased levels of Bax protein and decreased levels of Bcl-2 protein. The results of this study suggest that wogonoside may represent a potential therapeutic agent against $\mathrm{HCC}$.
\end{abstract}

\section{Introduction}

Hepatocellular carcinoma (HCC), the most common primary malignancy of the liver, is the sixth most common type of cancer worldwide and the third leading cause of cancer-related mortality (1). The number of cases diagnosed with HCC is expected to increase worldwide, particularly in East and Southeast Asia (1). Several lines of study demonstrate that the major risk factors of $\mathrm{HCC}$ include chronic hepatitis B or

Correspondence to: Dr Guanghua Lei, Department of Orthopaedics, Xiangya Hospital, Central South University, 87 Xiangya Road, Changsha, Hunan 410008, P.R. China

E-mail:373730165@qq.com

${ }^{*}$ Contributed equally

Key words: wogonoside, hepatocellular carcinoma, apoptosis, Bax
$\mathrm{C}$ virus infection, diabetes, non-alcoholic fatty liver disease, excessive alcohol consumption and dietary exposure to aflatoxin $(2,3)$. Despite substantial and accelerated research in the area of HCC, the 5-year survival rate for advanced disease remains $<10 \%$ (4). The first line of therapy consists of ablative therapy, surgical resection and transplantation (5). However, due to a shortage of donor livers, and patients' advanced tumor stage or liver dysfunction, less than $20 \%$ of HCC patients are eligible for these treatments (6). Therefore, there is a need to develop novel therapeutic approaches to improve the outcomes of patients with HCC.

Hepatocarcinogenesis is a complex, multi-step process which occurs as a result of a combination of epigenetic and genetic alterations. It has been reported that apoptosis, which triggers a range of extrinsic and intrinsic signals leading to cell shrinkage, blebbing of the plasma membrane, chromatin condensation and DNA laddering, plays a role in the development of neoplastic transformation and tumor growth (7). Accumulating evidence suggests that the dysregulation of the apoptotic process plays a crucial role in the occurrence and progression of human HCC (8). Therefore, a number of potential anticarcinogens, which induce the apoptotic process in various ways, may be applied in the management of HCC $(9,10)$.

In recent years, traditional Chinese medicines have slowly gained considerable attention as a new source of anticancer drugs. Although their curative mechanisms remain largely unknown, certain drugs have been used to treat cancer (11). Wogonin (5,7-dihydroxy-8-methoxy-2-phenylchromen-4-one, $\mathrm{C}_{16} \mathrm{H}_{12} \mathrm{O}_{5}$ ), a flavonoid extracted from the root of the traditional Chinese herb Scutellaria baicalensis, has been considered to be responsible for the therapeutic actions of Scutellaria baicalensis due to its observed pharmacological actions including anti-inflammation and anticancer properties, reduction of total cholesterol level and anti-HIV activity (12-14). Due to its therapeutic potential, wogonin has been recognized as a new source of anticancer drug and a new chemotherapy adjuvant to enhance the efficacy of chemotherapy and to ameliorate the side effects of cancer chemotherapies (13-16). Wogonoside (wogonin-7-glucuronide, $\mathrm{C}_{22} \mathrm{H}_{20} \mathrm{O}_{11}$ ), a metabolite of wogonin, is also derived from Scutellaria baicalensis, sharing the same flavone backbone as wogonin (17). Accumulating evidence demonstrates that 
wogonoside is involved in various biological and pathological processes including anti-inflammation, anti-angiogenesis, cell cycle arrest and induction of autophagy (18-21). The difference between the two chemical structures is the presence and placement of 7-glucuronic acid, indicating that wogonoside and wogonin may affect similar biochemical processes. Wogonin has been reported to kill HCC cells in vitro and inhibit tumor growth in vivo in a number of mouse tumor models $(15,16,22,23)$. All the properties of wogonoside mentioned above indicate that wogonoside may be involved in the anticancer process. However, as a metabolite of wogonin, relatively few studies have investigated the potential effects of wogonoside on HCC, and its antitumor properties have not been elucidated.

In the present study, the effects of wogonoside on cell apoptosis were evaluated in the human HCC cell line Bel-7402. The potential regulation pathway involved in its apoptotic effect was also investigated.

\section{Materials and methods}

Cell lines and reagents. The human liver cancer cell line Bel-7402 was donated by the State Key Laboratory of Medical Genetics of Central South University, Changsha, China. It was cultured in RPMI-1640 medium (Gibco, Grand Island, NY, USA) supplemented with $15 \%$ fetal bovine serum (Invitrogen Life Technologies, Carlsbad, CA, USA), $100 \mathrm{U} / \mathrm{ml}$ penicillin and $100 \mu \mathrm{g} / \mathrm{ml}$ streptomycin in a humidified incubator under $95 \%$ air and $5 \% \mathrm{CO}_{2}$ at $37^{\circ} \mathrm{C}$. Wogonoside, kindly provided by the Pharmacy College of Central South University, was first dissolved in phosphate-buffered saline (PBS) to prepare $10 \mathrm{mg} / \mathrm{ml}$ store solution and then serially diluted to various concentrations prior to experiments. The present study was approved by the ethics committee of Xiangya Hospital, Central South University (Changsha, China).

Measurement of cell viability. 3-(4,5-dimethylthiazol-2-yl)2,5-diphenyltetrazolium bromide (MTT) assay was used to evaluate the cell viability according to the manufacturer's instructions (Sigma-Aldrich, St. Louis, MO, USA). Briefly, $1 \times 10^{4}$ cells per well were plated onto 96 -well plates and incubated for $3 \mathrm{~h}$. The cells were then treated with wogonoside at the indicated concentrations $(1,2,4,8,16,32,64,128,256$ and $512 \mu \mathrm{M}$, and 1 and $2 \mathrm{mM}$ ) for $48 \mathrm{~h}$. Each experiment was performed in triplicate. MTT reagent was added. Following incubation for $4 \mathrm{~h}$ at $37^{\circ} \mathrm{C}$, the absorbance, which is directly proportional to the number of viable cells in cultures, was measured at $570 \mathrm{~nm}$ using a microplate reader (Mithras LB940 multilabel reader; Berthold Technologies, Bad Wildbad, Germany). The cell viability was expressed as a percentage value of control cells cultured with medium alone. The test was run three times and the inhibition rate was calculated with the formula: Inhibition rate $=1-\left[\left(\right.\right.$ Treatment $_{\mathrm{A} 570}-$ Blank $\left._{\mathrm{A} 570}\right) /$ $\left.\left(\mathrm{Control}_{\mathrm{A} 570}-\mathrm{Blank}_{\mathrm{A} 570}\right)\right] \times 100 \%$ to produce an inhibition curve and derive the half maximal inhibitory concentration $\left(\mathrm{IC}_{50}\right)$ of wogonoside.

DNA ladder assay was also performed as previously described (24). Briefly, Bel-7402 cells were cultured in a $25-\mathrm{mm}^{2}$ flask with $4,8,12$ and $16 \mu \mathrm{M}$ wogonoside at $\sim 2 \times 10^{6}$ cells per group for DNA sample extraction. The control group were treated with $100 \mu \mathrm{M}$ 5-fluorouracil (5-FU; Sigma-Aldrich).

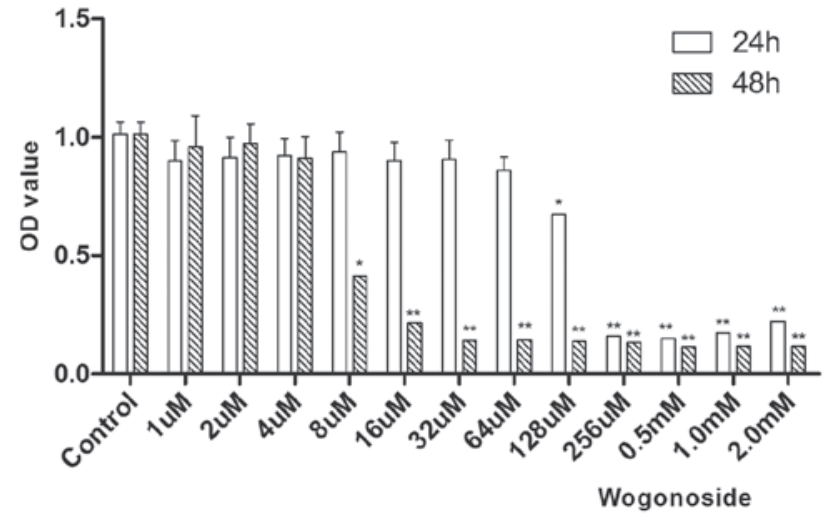

Figure 1. Effects of wogonoside on the proliferation of hepatocellular carcinoma cells. Cells were treated with various concentrations of wogonoside for the indicated times $(24$ and $48 \mathrm{~h})$ and subjected to 3-(4,5-dimethylthiazol2-yl)-2,5-diphenyltetrazolium bromide assay. Each reported value is the mean \pm standard deviation of at least three independent experiments performed in triplicate. ${ }^{*} \mathrm{P}<0.05$ and ${ }^{* *} \mathrm{P}<0.01$ compared with control group.

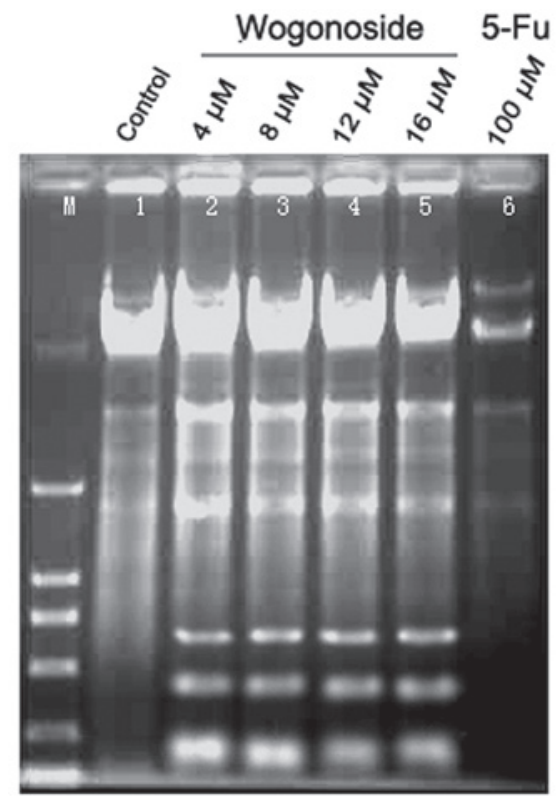

Figure 2. DNA fragmentation of Bel-7402 following wogonoside treatment for $24 \mathrm{~h}$. Bel-7402 cells were treated with various concentrations $(4,8,12$, $16 \mu \mathrm{M})$ of wogonoside and 5-fluorouracil (5-FU; $100 \mu \mathrm{M})$. Integrity of DNA was assessed through a $1.2 \%$ agarose gel and visualized by staining with ethidium bromide.

Cells were harvested at 12, 24, 36 and $48 \mathrm{~h}$ after treatment. DNA was electrophoresed in $1.2 \%$ agarose gels at $10 \mathrm{~V} / \mathrm{cm}$ for $2 \mathrm{~h}$. The analysis of DNA fragmentation was carried out using the manufacturer's apoptotic DNA ladder kit (Calbiochem, Billerica, CA, USA).

Flow cytometry for cell cycle detection. Cells were plated in $35-\mathrm{mm}$ dishes at concentrations determined to yield $60-70 \%$ confluence within $48 \mathrm{~h}$ and then treated with wogonoside at the indicated concentrations $(4,8,12$ and $16 \mu \mathrm{M})$ for $48 \mathrm{~h}$. The adherent and floating cells were harvested, and the cells were resuspended in PBS, and fixed with $70 \%$ ethanol at $-20^{\circ}$ overnight. The cells were first incubated with RNaseA (20 U/ml; Sigma-Aldrich) at $37^{\circ} \mathrm{C}$ for $30 \mathrm{~min}$ and then labeled 
A

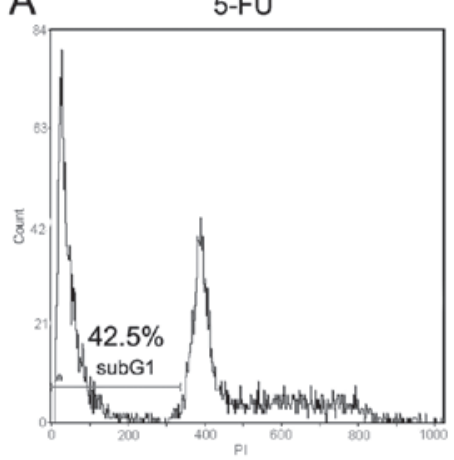

D

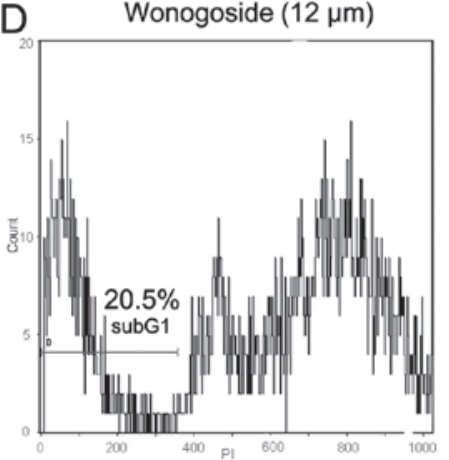

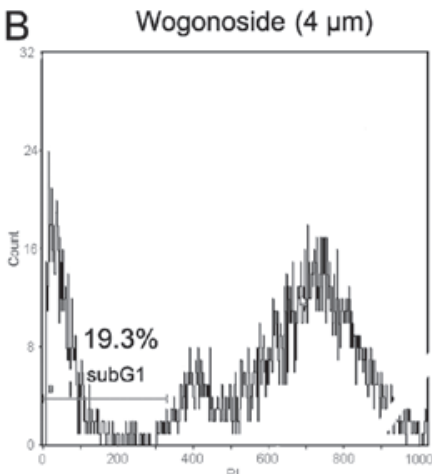
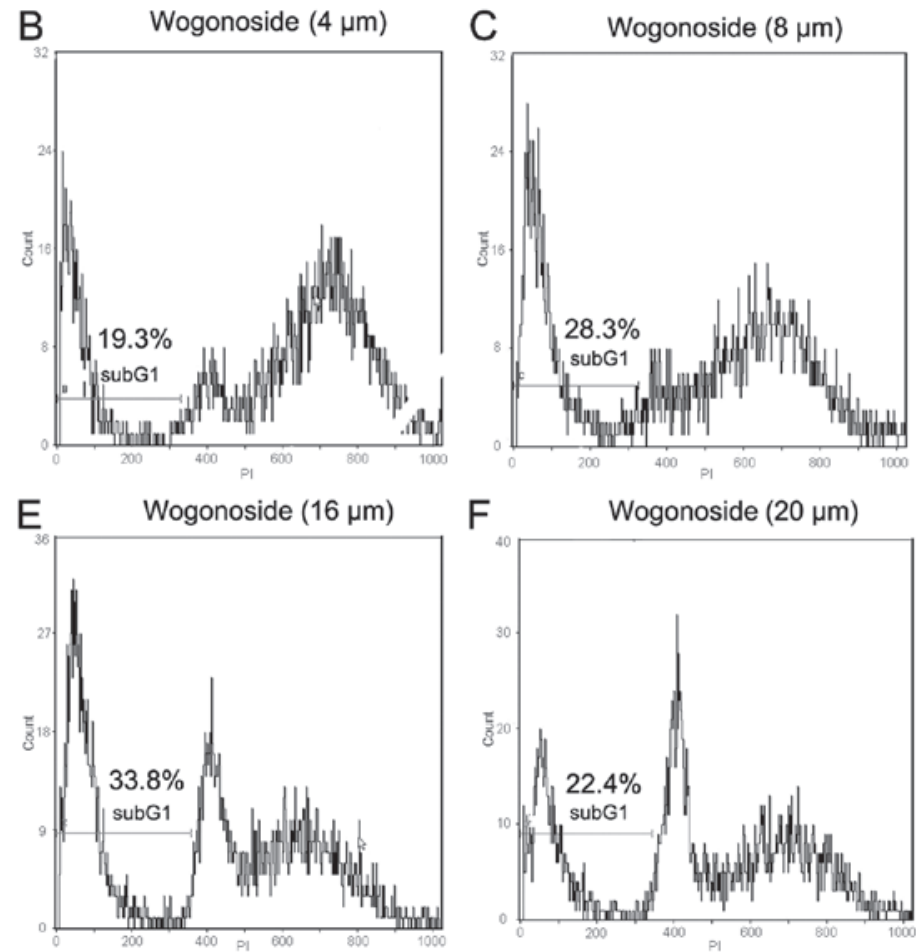

Figure 3. Effect of wogonoside on cell cycle of hepatocellular carcinoma cells. Bel-7402 cells were treated with (A) 5-fluorouracil (control) or (B-F) various concentrations $(4,8,12,16$ and $20 \mu \mathrm{M})$ of wogonoside, and the ratio of hypodiploid cells was measured by flow cytometry analysis by propidium iodide staining. Each value is presented as the mean $\pm \mathrm{SE}$ of three independent experiments.

with propidium iodide $(50 \mu \mathrm{g} / \mathrm{ml})$ and incubated at room temperature in the dark for $30 \mathrm{~min}$. DNA content was then analyzed using a FACScan instrument equipped with FACStation running CellQuest software (Becton-Dickinson, San Jose, CA, USA).

Western blotting of Bcl-2, Bax and p53 expression. Western blotting was performed to assess Bcl-2, Bax and p53 expression as previously described (25). Briefly, a total of $10^{6}$ cells were sedimented and lysed for $15 \mathrm{~min}$ in ice-cold lysis buffer $[0.1 \%$ sodium dodecyl sulphate (SDS), 1\% NP-40, 50 mM HEPES, pH 7.4, 2 mM ethylenediaminetetraacetic acid, $100 \mathrm{mM} \mathrm{NaCl}$, $5 \mathrm{mM}$ sodium orthovanadate, $40 \mu \mathrm{M}$ p-nitrophenyl phosphate and $1 \%$ protease inhibitor mixture set I; Calbiochem, Billerica, MA, USA]. After removing the cell debris by centrifugation at $16,200 \mathrm{x} g$ for $15 \mathrm{~min}$, equal amounts of proteins were separated on $12 \%$ SDS polyacrylamide gel, blotted onto a nitrocellulose membrane (GE Healthcare, Little Chalfont, UK) and blocked with 5\% nonfat dry milk in PBS/Tween $(0.05 \%$ Tween-20 in PBS). Bcl-2, Bax and p53 antibodies were used (all from Santa Cruz Biotechnology, Santa Cruz, CA, USA). The membranes were then incubated with the appropriate horseradish peroxidase-conjugated secondary antibodies (1:2000). The immunoreactive protein bands were developed by enhanced chemiluminescence.

Statistical analysis. Data are expressed as the means \pm standard deviation. Statistical analysis was performed using SPSS software version 17.0 (SPSS, Inc., Chicago, IL, USA). The difference between two groups was analyzed by Student's t-test. $\mathrm{P}<0.05$ was considered to indicate a statistically significant difference.

\section{Results}

Proliferative inhibition and cell cycle arrest by wogonoside. To examine the effect of wogonoside on the cell viability in HCC cells, MTT assay was performed first. Cell viability was dose-dependently reduced in Bel-7402 liver cancer cells following wogonoside treatment at the indicated concentrations for $24 \mathrm{~h}$ (Fig. 1). Wogonoside inhibited Bel-7402 cells with an $\mathrm{IC}_{50}$ value of $8 \mu \mathrm{M}$. The results of the DNA ladder assay revealed that cells from the control group presented an intact band of genomic DNA whereas the 5-FU and wogonoside treatment group did not (Fig. 2). The effect of wogonoside on the cell cycle progression of Bel-7402 was also examined. Cell cycle analysis revealed that exposure to wogonoside $(4 \mu \mathrm{M})$ for $24 \mathrm{~h}$ induced the accumulation of a significant proportion of cells in the G2/M phase (Fig. 3). The data above suggest that wogonoside treatment induced apoptosis in the HCC cell line.

Inhibition of Bcl-2 protein enhances the apoptosis-inducing activity of wogonoside. The potential effects of wogonoside were investigated in $\mathrm{HCC}$ cells. The pro-apoptotic Bax protein is among a number of key regulators of apoptosis. Therefore, the effects of wogonoside were investigated in this regulatory protein. We observed that wogonoside increased Bax expression in HCC cells in the western blotting assay (Fig. 4), which suggests that wogonoside promotes HCC cell apoptosis via the Bax protein regulatory pathway. The expression of anti-apoptotic protein $\mathrm{Bcl}-2$ was also examined in this study. Bcl-2 expression was revealed to be decreased in the western blotting assay (Fig. 4). The expression of p53 protein was also 


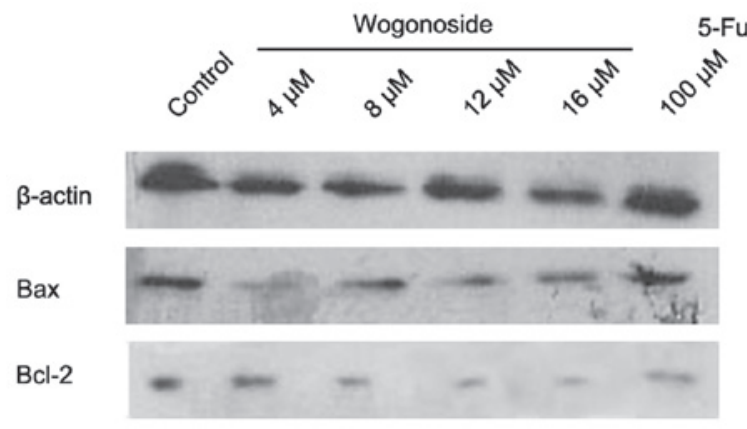

Figure 4. Effect of wogonoside on the expression of Bax, Bcl-2 in Bel-7402 cells. Bel-7402 cells were treated with various concentrations $(4,8,12$, $16 \mu \mathrm{M}$ ) of wogonoside and 5-fluorouracil (5-FU; $100 \mu \mathrm{M}$ ). Bax and Bcl-2 proteins were analyzed by western blotting using specific antibodies.

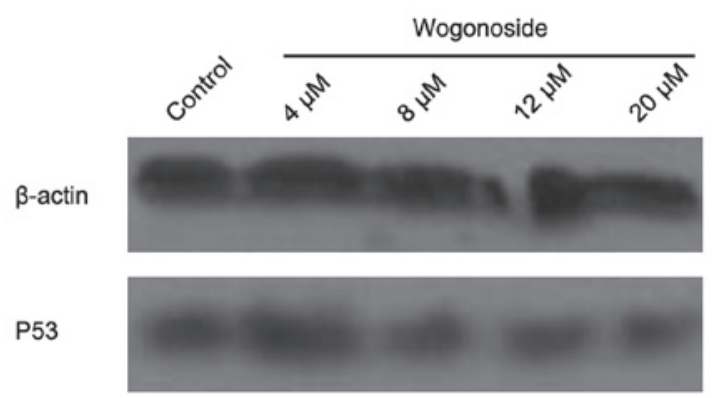

Figure 5. Effect of wogonoside on the expression of p53 in Bel-7402 cells. Bel-7402 cells were treated with various concentrations $(4,8,12,20 \mu \mathrm{M})$ of wogonoside and the 533 protein were analyzed by western blotting.

detected in the study (Fig. 5). Western blotting assay did not reveal any significant change in $\mathrm{p} 53$ expression.

\section{Discussion}

Herbs have been used successfully in traditional Chinese medicine for centuries; however, their therapeutic mechanism remains unknown. The present study demonstrates that wogonoside, a major constituent of Scutellaria baicalensis, attenuated in vitro proliferation of the HCC cell line Bel-7402 by inducing apoptosis and downregulating Bax/Bcl-2 signaling pathways. These results reveal that an adjuvant therapy of wogonoside may have potential therapeutic benefits for HCC.

Scutellaria baicalensis is often used for the treatment of inflammation, cardiovascular disease, and respiratory and gastrointestinal infection (26). The anticancer effect of Scutellaria baicalensis extract has recently become a topic of interest. Moreover, a number of in vitro studies suggest that the extract of Scutellaria baicalensis inhibits the growth of various cancer cell lines through specific biological signaling pathways, including apoptosis, angiogenesis and inhibition of the androgen receptor $(15,16,18-23)$.

Increasing evidence has demonstrated that wogonoside, a major extract of Scutellaria baicalensis, induces autophagy in MDA-MB-231 cells by regulating the MAPK-mTOR pathway (19). It also participates in cell cycle arrest and differentiation by regulating the expression and subcellular localization of PLSCR1 in AMl cells (20). Moreover, wogonoside induces the inhibition of lipopolysaccharide-induced angiogenesis in vitro and in vivo via toll-like receptor 4 signal transduction (21). The present study confirmed that wogonoside possesses the ability to induce cycle arrest and apoptosis in HCC cells, indicating that the glucuronide metabolite wogonoside, like its aglycone wogonin, possesses biological activity.

Apoptosis represents a physiological means of eliminating excess cells during liver development and regeneration (27). Apoptotic cell death is initialized through the extrinsic or intrinsic signaling pathways that are ultimately coupled to the activation of the effect of caspases. The extrinsic pathway is largely controlled by the pro-apoptotic (e.g. Bax, Bad, Bid and Bak) and anti-apoptotic (e.g. Bcl-2 and Bcl-xL) Bcl-2 family proteins. It has been reported that the induction of mitochondrial apoptosis requires the involvement of the $\mathrm{Bcl}-2$ family (28). The Bcl-2 family is comprised of proteins that share a Bcl-2 homology region and undergo heterodimerization or homodimerizaton (29). The ratio between anti- and pro-apoptotic proteins is considered a determinant for tissue homeostasis since it influences the sensitivity of cells to inducers of apoptosis (30).

In this study, it was demonstrated that the induction of apoptosis by wogonoside in HCC cells is associated with increased expression of the pro-apoptotic protein Bax and decreased expression of the anti-apoptotic protein Bcl-2. A wogonin-induced decreased ratio of Bcl-2 to Bax and increased expression of cleaved caspase 3 and 9 has been demonstrated in human breast cancer cells (31). Wogonoside, derived from Scutellaria baicalensis, shares the same flavone backbone as wogonin. Similar results were obtained in our study. Therefore, it is reasonable to assume that wogonoside-induced apoptosis of HCC cells is mediated by the mitochondrial pathway by altering the ratio of $\mathrm{Bcl}-2$ to Bax.

The $\mathrm{p} 53$ protein, which acts as a guardian of the genome, is one of the key factors controlling cell proliferation, suppressing the growth and transformation of cells. Mutations in the p53 tumor suppressor gene are among the most common alterations observed in HCC (10). Various chemotherapeutic agents require p53 to induce apoptosis. Thus, we investigated p53 protein expression induced by wogonoside in HCC cells. There was no significant alteration observed in the western blotting assay. The results revealed that there may not be a correlation between wogonoside-induced apoptosis and the p53 pathway in HCC cells.

In conclusion, wogonoside may act as an effective drug with anti-proliferative and apoptotic activity in HCC cells. This study also presented a molecular mechanism responsible for the effects; namely, downregulation of the Bcl-2/Bax signaling pathway in wogonoside-induced apoptosis. The results of this study suggest that wogonoside may represent a potential therapeutic agent against HCC.

\section{Acknowledgements}

This study was supported by grants from the National Natural Science Foundation of China (nos. 81201420, 81272034 and 81472130), the Provincial Science Foundation of Hunan (no. 14JJ3032), the Scientific Research Project of the Development and Reform Commission of Hunan 
Province [no. (2013)1199], the Scientific Research Project of the Science and Technology Office of Hunan Province (no. 2013SK2018), the Doctoral Scientific Fund Project of the Ministry of Education of China (no. 20120162110036), and the Fundamental Research Funds for the Central Universities of Central South University (no. 2013zzts319).

\section{References}

1. Forner A, Llovet JM and Bruix J: Hepatocellular carcinoma. Lancet 379: 1245-1255, 2012

2. Bridges JF, Joy SM, Gallego G, Kudo M, Ye SL, Han KH, Cheng AL and Blauvelt BM: Needs for hepatocellular carcinoma control policy in the Asia-Pacific region. Asian Pac J Cancer Prev 12: 2585-2591, 2011.

3. Sherman M: Hepatocellular carcinoma: epidemiology, surveillance and diagnosis. Semin Liver Dis 30: 3-16, 2010.

4. Olsen SK, Brown RS and Siegel AB: Hepatocellular carcinoma: review of current treatment with a focus on targeted molecular therapies. Therap Adv Gastroenterol 3: 55-66, 2010.

5. EI-Serag HB: Hepatocellular carcinoma. N Engl J Med 365: 1118-1127, 2011.

6. Davila JA, Duan Z, McGlynn KA and El-Serag HB: Utilization and outcomes of palliative therapy for hepatocellular carcinoma: a population-based study in the United States. J Clin Gastroenterol 46: 71-77, 2012.

7. Riedl SJ and Salvesen GS: The apoptosome: signalling platform of cell death. Nat Rev Mol Cell Biol 8: 405-413, 2007.

8. Fabregat I, Roncero C and Fernández M: Survival and apoptosis: a dysregulated balance in liver cancer. Liver Int 27: 155-162, 2007.

9. Fransvea E, Angelotti U, Antonaci S and Giannelli G: Blocking transforming growth factor-beta up-regulates E-cadherin and reduces migration and invasion of hepatocellular carcinoma cells. Hepatology 47: 1557-1566, 2008.

10. Hussain SP, Schwank J, Staib F, Wang XW and Harris CC: TP53 mutations and hepatocellular carcinoma: insights into the etiology and pathogenesis of liver cancer. Oncogene 26 2166-2176, 2007.

11. Normile D: Asian medicine. The new face of traditional Chinese medicine. Science 299: 188-190, 2003.

12. Yoon SB, Lee YJ, Park SK, Kim HC, Bae H, Kim HM, Ko SG, Choi HY, Oh MS and Park W: Anti-inflammatory effects of Scutellaria baicalensis water extract on LPS-activated RAW 264.7 macrophages. J Ethnopharmacol 125: 286-290, 2009.

13. Li-Weber M: New therapeutic aspects of flavones: the anticancer properties of Scutellaria and its main active constituents Wogonin, Baicalein and Baicalin. Cancer Treat Rev 35: 57-68, 2009.

14. Burnett BP, Jia Q, Zhao Y and Levy RM: A medicinal extract of Scutellaria baicalensis and Acacia catechu acts as a dual inhibitor of cyclooxygenase and 5-lipoxygenase to reduce inflammation. J Med Food 10: 442-451, 2007.

15. Zhao Q, Wang J, Zou MJ, Hu R, Zhao L, Qiang L, Rong JJ, You QD and Guo QL: Wogonin potentiates the antitumor effects of low dose 5-fluorouracil against gastric cancer through induction of apoptosis by down-regulation of NF-kappaB and regulation of its metabolism. Toxicol Lett 197: 201-210, 2010.
16. Enomoto R, Koshiba C, Suzuki C and Lee E: Wogonin potentiates the antitumor action of etoposide and ameliorates its adverse effects. Cancer Chemother Pharmacol 67: 1063-1072, 2011.

17. Li C, Lin G and Zuo Z: Pharmacological effects and pharmacokinetics properties of Radix Scutellariae and its bioactive flavones. Biopharm Drug Dispos 32: 427-445, 2011.

18. Yang YZ, Tang YZ and Liu YH: Wogonoside displays anti-inflammatory effects through modulating inflammatory mediator expression using RAW264.7 cells. J Ethnopharmacol 148: 271-276, 2013.

19. Sun Y, Zou M, Hu C, Qin Y, Song X, Lu N and Guo Q: Wogonoside induces autophagy in MDA-MB-231 cells by regulating MAPK-mTOR pathway. Food Chem Toxicol 51: 53-60, 2013.

20. Chen Y, Hui H, Yang H, Zhao K, Qin Y, Gu C, Wang X, Lu N and Guo Q: Wogonoside induces cell cycle arrest and differentiation by affecting expression and subcellular localization of PLSCR1 in AMl cells. Blood 121: 3682-3691, 2013.

21. Chen Y, Lu N, Ling Y, Gao Y, Wang L, Sun Y, Qi Q, Feng F, Liu W, Liu W, You Q and Guo Q: Wogonoside inhibits lipopolysaccharide-induced angiogenesis in vitro and in vivo via toll-like receptor 4 signal transduction. Toxicology 259: 10-17, 2009.

22. Chow SE, Chang YL, Chuang SF and Wang JS: Wogonin induced apoptosis in human nasopharyngeal carcinoma cells by targeting GSK- $3 \beta$ and $\Delta$ Np63. Cancer Chemother Pharmacol 68: 835-845, 2011.

23. Baumann S, Fas SC, Giaisi M, Müller WW, Merling A, Gülow K, Edler L, Krammer PH and Li-Weber M: Wogonin preferentially kills malignant lymphocytes and suppresses T-cell tumor growth by inducing PLCgamma1-and Ca2+-dependent apoptosis. Blood 111: 2354-2363, 2008.

24. Roy M, Chakraborty S, Siddiqi M and Bhattacharya RK: Induction of apoptosis in tumor cells by natural phenolic compounds. Asian Pac J Cancer Prev 3: 61-67, 2002.

25. Dang YM, Huang G, Chen YR, Dang ZF, Chen C, Liu FL, Guo YF and Xie XD: Sulforaphane inhibits the proliferation of the BIU87 bladder cancer cell line via IGFBP-3 elevation. Asian Pac J Cancer Prev 15: 1517-1520, 2014.

26. Yu J, Liu H, Lei J, Tan W, Hu X and Zou G: Antitumor activity of chloroform fraction of Scutellaria barbata and its active constituents. Phytother Res 21: 817-822, 2007.

27. Guicciardi ME and Gores GJ: Apoptosis: a mechanism of acute and chronic liver injury. Gut 54: 1024-1033, 2005.

28. Brunelle JK and Letai A: Control of mitochondrial apoptosis by the Bcl-2 family. J Cell Sci 122: 437-441, 2009.

29. Steinbach JP and Weller M: Apoptosis in Gliomas: Molecular Mechanisms and Therapeutic Implications. J Neurooncol 70: 247-256, 2004.

30. Korsmeyer SJ: BCL-2 gene family and the regulation of programmed cell death. Cancer Res 59 (Suppl 7): 1693-1700, 1999.

31. Chung H, Jung YM, Shin DH, Lee JY, Oh MY, Kim HJ, Jang KS, Jeon SJ, Son KH and Kong G: Anticancer effects of wogonin in both estrogen receptor-positive and -negative human breast cancer cell lines in vitro and in nude mice xenografts. Int J Cancer 122: 816-822, 2008. 